\title{
Educação por meio da Gastronomia: mapeamento dos produtores de truta- arco- íris, relato de uma experiência pelo desenvolvimento rural regional da Serra da Mantiqueira e Vale do Paraíba paulistas
}

Education through Gastronomy: the mapping of trout (Oncorhynchusmykiss) producers, a report of an experience for the regional rural development of Serra da Mantiqueira and Vale do Paraiba

\section{Roseli de Sousa Neto}

Centro Universitário Senac - Campos do Jordão - São Paulo - Brasil

\section{Lygia Amadi da Silva Pinto}

Centro Universitário Senac - Campos do Jordão - São Paulo - Brasil

\section{Paula de Oliveira Feliciano}

Centro Universitário Senac - Campos do Jordão - São Paulo - Brasil

\begin{abstract}
Resumo: Este artigo busca realizar uma breve reflexão sobre conexões de aprendizagem possíveis por meio do estudo da gastronomia aliada ao espaço rural. Ao inserir o estudante em seu contexto pelo estudo das práticas alimentares proporciona-se uma aprendizagem mais significativa e benéfica a transformações coletivas, objetivo do ensino superior no século XXI. O presente estudo também revisa trabalhos que relacionam a Educação, Gastronomia, Geografia e Ciências Sociais, além de relatar uma experiência de ensino-aprendizagem por meio da gastronomia na Serra da Mantiqueira e Vale do Paraíba paulistas, o mapeamento de produtores de trutas, em 2016
\end{abstract}

Palavras-chave: Educação. Gastronomia. Truta arco-íris. Desenvolvimento Rural.

\begin{abstract}
This article tries to make a brief reflection on important learning connections and possible through the study of gastronomy allied to the rural. When entering the student in context by studying feeding practices, it provides a more meaningful and beneficial learning to collective transformations, higher education goal in the twentyfirst century. This study also reviews papers relating to Education, Food, Geography and Social Sciences and, in addition, reports a teaching-learning experience through gastronomy in the Serra da Mantiqueira and Vale do Paraíba, the mapping of trout producers, in 2016.
\end{abstract}

Keywords: Education. Gastronomy. Trout. Rural Development. 


\section{Introdução}

A alimentação, visto sua necessidade fisiológica e, por isso essencial, está aportada na cultura cotidiana do ser humano tanto em relação à natureza, aos meios, às formas e circunstâncias de preparo e consumo, influenciando os comportamentos e a cultura material. Reflete, portanto, na diferenciação dos grupos e estruturas sociais e, neste sentido, auxilia a construção de uma identidade. (WÄTZOLD, 2012)

Poulain (2013, p.34) reforça ainda que os

"produtos alimentares (quer seja ou não elaborados), objetos e habilidades utilizados em sua produção, em sua transformação, em sua conservação e em seu consumo, assim como os códigos sociais, 'os modos de cozinhar' e os 'modos comer e beber' são objetos culturais" [que possuem] "uma parte da história e da identidade de um grupo social".

Neste sentido, e ainda sob o reflexo da constituição de uma identidade brasileira por meio da cozinha, segundo Wätzold (2012, p.211) há que se ressaltar o papel da alimentação na "consolidação duradoura de outras identidades; (...) a alimentação regional representa um modelo de identificação extremamente importante, pelo qual a região e seus habitantes se representam para fora". As cozinhas regionais, assim como as próprias designações de seus habitantes (paulistas, mineiros, nordestinos, gaúchos, etc.) foram estabelecidas, e se cristalizaram, de acordo com as divisões geopolíticas. Contradição esta porque não consideram o material natural - a biodiversidade - que é próprio e inerente às escolhas e ao fazer culinário.

O estudo dos ingredientes regionais, sob 0 ponto de vista da biodiversidade, é uma estratégia de aprendizado ativa porque integra o estudante ao contexto rural e propicia o reconhecimento de seus aspectos histórico, político, cultural e social, reforçando a função que deve ser assumida pelo ensino superior: formação de um profissional competente, cidadão, com habilidades críticas e reflexivas e que é corresponsável pela sociedade em que vive.
Assim, vivenciar um aprendizado sob o contexto da gastronomia pode contribuir com o aprofundamento de ações objetivas em prol do desenvolvimento rural local, conforme se pretende apresentar no presente estudo.

O primeiro tópico deste artigo inicia-se com uma breve revisão bibliográfica que correlaciona a educação por meio da gastronomia quanto às possiblidades de ampliação da percepção de mundo, aprendizado responsável sobre o meio ambiente e (re)conhecimento da comunidade local.

O segundo tópico caracteriza a truta arco-íris dentro dos limites geográficos pretendidos por esse artigo, Campos do Jordão e arredores, compreendendo a Serra da Mantiqueira e Vale do Paraíba paulistas. Pretende-se contextualizá-la histórica, cultural, organoléptica e nutricionalmente.

Já o terceiro tópico busca consolidar a proposta teórica com o relato de uma experiência de aprendizado por meio da gastronomia aliada ao desenvolvimento rural local: o mapeamento dos produtores de trutas na Serra da Mantiqueira e Vale do Paraíba paulistas. Por último, o momento das considerações finais sobre a vocação da gastronomia como auxiliar no processo do fortalecimento do pertencimento rural e alternativa para o desenvolvimento turístico.

\subsection{Metodologia}

Propõe-se neste artigo pesquisa qualitativa com o objetivo de explorar - sem esgotar o assunto estudos direcionados a relacionar conexões de aprendizagem possíveis por meio do estudo da gastronomia aliada ao ambiente natural. Para tal, utilizou-se de revisão bibliográfica em publicações e periódicos presentes nas bases de dados Scielo, Capes e sítios da internet utilizando as palavraschaves educação, gastronomia e geografia. Foi realizado levantamento sobre os produtores de truta arco-íris existentes nos arredores da Serra da Mantiqueira e Vale do Paraíba paulistas; e este apresentado como relato de uma experiência que visa revelar uma possibilidade de aprendizado por meio da 
gastronomia que contribui para o desenvolvimento rural, em 2016.

\section{Educação por meio da gastronomia:} ampliação da percepção de mundo, aprendizado responsável sobre o ambiente rural e a comunidade

A constituição do paladar de um povo, conforme elucida Maciel (2005, apud CANESQUI, p.55), pode seguir diversos caminhos. Da simples utilização de elementos locais como animais, plantas e temperos, à mescla de hábitos, costumes e necessidade alimentares de grupos populacionais participantes de deslocamentos territoriais completam o conjunto de fatores que determinam preferências, interdições, prescrições, associações e exclusões alimentares.

A noção de pertencimento social também encontra fundamento quando se visualiza a natureza interdisciplinar da gastronomia. Ela dialoga com as ciências humanas, sociais aplicadas e da natureza. Envolve, portanto, mais do que mistura de ingredientes, compreende noções antropológicas e sociológicas de regras, rituais, procedências, territórios e, identidades. Claude Lévi-Strauss (apud MENEZES, 2005, p. 3) diz que

a cozinha estabelece uma identidade entre nós, constitui o meio universal pelo qual a natureza é transformada em cultura e é também uma linguagem por meio da qual "falamos" sobre nós próprios e sobre nossos lugares no mundo.

O valor comunicativo daquilo que se come, como se come e com quem se come faz com que o indivíduo se considere inserido em um contexto sociocultural que the outorga identidade, reafirmada pela memória gustativa. Estes sistemas alimentares permitem que ele perceba sua distinção, se reconheça e se veja reconhecido.

A constituição de sistemas alimentares propõe a reunião de fatores de ordem espacial, ecológica, histórica, cultural, social e econômica comuns a um grupo de pessoas e que, juntos, estabelecem as relações dos homens entre si e com a natureza. No processo de construção e afirmação dessas identidades, os sistemas alimentares, como símbolos que representam elementos culturais, se transformam em marcadores identitários, adquiridos ou apropriados durante a história da construção de uma comunidade e transmitido às gerações seguintes no processo de socialização.

Perante o fenômeno da globalização, que torna homogêneo os repertórios alimentares, percebe-se a necessidade crescente de afirmação da identidade de um povo. A comida preenche todas as condições simbólicas para valorizar e fortalecer a cultura da qual se originou e justificar a identidade de uma comunidade. As cozinhas nacionais e regionais, pautadas na memória gustativa e na utilização de ingredientes locais, consolidam e fornecem sentido à vida coletiva.

A gastronomia como contexto da aprendizagem possibilita, assim, conectar os indivíduos com o mundo ao seu redor, ampliando sua percepção por meio da união e estímulo dos seus sentidos sensoriais vitais envolvidos na alimentação: tato, paladar, audição, visão e olfato. Ou seja, o próprio corpo como instrumento e porta de entrada para a aprendizagem, o que torna a experiência ainda mais consciente e com possibilidades reais de transformação. (GOLDSCHMIDT et al, 2008).

Aprender sobre alimentação propõe conexões diversas, construção de ideias e conhecimento humano, também propícias para a afirmação de um elo afetivo entre pessoa e o lugar, nas palavras de Tuan (1980), 'topofilia', um sentimento capaz de significar essa relação para a compreensão da memória e da cultura.

Como experiência concreta pessoal, esta conexão media a experiência ambiental e espacial pois permite visualizar e sensibilizar para as interrelações entre a alimentação e o planeta, com o propósito de fortalecer o exercício da cidadania (e seus significados culturais) com ações que promovam um desenvolvimento sustentável. Sobre essas relações, destacam Gratão e Marandola Jr (2011, p.62): 
O sabor está "enraizado" na geograficidade, ligação essencial, telúrica, homem-Terra. É assim que o enveredar-se por esse campo da Geografia parte de um fazer enraizado na valoração da paisagem e da cultura. O sabor que brota da terra, que envolve valores culturais, éticos e humanos, numa relação que ultrapassa o inventário dos conteúdos da área e de seus objetos. Uma relação que se estabelece no modo de ver o mundo, aos seus padrões objetivos, mas também às crenças das pessoas, aos significados subjetivos dos lugares.

Da relação destes conceitos, pode-se inferir que o meio ambiente natural, no qual se estabelece o estudo da gastronomia, gera uma possibilidade de aprendizado também constituída de sentimento, o que proporciona, necessariamente, proximidade e envolvimento, elementos para uma experiência que incluirá a compreensão da própria existência e da sua comunidade.

A conexão da alimentação com o meio rural produz formas únicas de habitar o mundo e traz à tona as identidades culturais. Montanari (2008, p.15) afirma que "os valores de base do sistema alimentar [...] são como resultado e representação de processos culturais que prevêem a domesticação, a transformação, a reinterpretação da natureza". Favorece, assim, reflexões em direção à conscientização, conservação e preservação do meio ambiente. (Gratão e Marandola Jr, 2011)

A qualidade do espaço natural, incluindo as relações de produção nele existentes, acrescentam características organolépticas aos produtos/ingredientes em função do solo, clima, temperatura, insolação, particularidades genéticas, de nutrição e precipitação. Esta noção de terroir, termo da gastronomia associada ao espaço, contribui como estratégia para o desenvolvimento sustentável rural, porque pode produzir uma marca distintiva local. (DÓRIA, 2009)

A importância vital da alimentação para o ser humano reside na sua própria existência e relação com o mundo, o que viabiliza abertura para a apreensão de saberes e responsabilidades individuais e coletivas na manutenção e gestão desse bem natural. Estas se configuram desde a preocupação com a qualidade dos alimentos em si e desdobram-se nas atividades a ela relacionadas, desde o cultivo, produção, beneficiamento, industrialização, fazer culinário, venda, consumo e prática de políticas públicas. (PETRINI et al, 2012).

Dentre as possibilidades de conexões de aprendizado por meio da gastronomia e que oportunizam a ampliação da percepção de mundo, responsabilidade sobre o meio rural e a comunidade, destacam-se:

- Agricultura e pecuária sustentáveis, que se preocupem em como suas atividades impactam a fertilidade do solo, salubridade da água e do ar e condições justas de trabalho a seus trabalhadores;

- Defesa da biodiversidade: por meio de práticas que respeitem a soberania alimentar e saberes tradicionais dos povos;

- Saúde nutricional: expressa por alimentos não processados, nem ultraprocessados;

- Fazer culinário: utilização integral dos alimentos, evitando os desperdícios. Estes trazem reflexões sobre quem compra ou produz alimentos em excesso e sua distribuição.

- Prazer, sociabilidade, convívio e compartilhamento: relação imaterial inerente à alimentação e que significa a manutenção dos conhecimentos culturais;

- Memória e identidade cultural: permite reavaliar as perspectivas eurocêntricas e hegemônicas dando espaço ao protagonismo das culturas sobre saberes locais (mulheres, agricultores e idosos como seus principais guardiães e transmissores).

- Economia local e democracia participativa: produzir em pequena escala pois são estes que zelam pelos recursos naturais e do território sendo, assim, uma forma direta de democracia participativa pela possibilidade ativa da escolha sobre o que e como produzir alimentos;

- Políticas públicas: o direito ao alimento é o direito primário da humanidade, que é essencial para sua sobrevivência. Segundo Petrini (2012), este direito impõe aos governos a obrigação de respeitar, proteger e permitir o acesso dos mais necessitados a 
esses recursos. Ou seja, implica criar políticas públicas adequadas e assistência direta em casos extremos de fome.

As escolhas alimentares estão condicionadas a aspectos plurais como regras, rituais, procedências, valores éticos e religiosos e têm forte valor comunicativo, transmitindo entendimentos coletivos sobre a natureza da vida. A educação por meio da gastronomia pode, então, contribuir não só para o seu (re)conhecimento e celebração, mas para ativar o sentimento de solidariedade e pertencimento que conduzirá ao entendimento mais estreito sobre homem-lugar, percepção de atitudes, responsabilidades e o valor da sua cidadania, conduzindo ações objetivas virtuosas para o desenvolvimento local.

\subsection{Caracterização da truta arco-íris em Campos do Jordão e arredores}

A Serra da Mantiqueira, famosa por suas paisagens, montanhas e cachoeiras, também oferece ao mercado local e regional uma abundante produção de trutas (HERRMANN; COSTA, 2012). A espécie mais característica da região é a truta arco-íris, oncorhynchusmykiss, encontrada na água doce e introduzida no Brasil em 1949, por iniciativa do ministério da Agricultura. Vinte anos depois, no começo dos anos 1970, o Brasil passou a fabricar ração e a entender como se faz a reprodução das trutas em tanques, visando a comercialização do produto. Para o morador de Campos do Jordão, as criações de trutas são encontradas em diversas propriedades, espalhadas pela serra e valorizadas pelo turismo e pela gastronomia. A carne é de excelente qualidade, elevado valor comercial, e alto grau de domesticação (SATO, TABATA, TAKAHASHI, 2010).

Campos do Jordão é uma das sete cidades que compõem o Circuito da Mantiqueira, juntamente com Piquete, Pindamonhangaba, São Bento do Sapucaí, São Jose dos Campos, Monteiro Lobato, São Francisco Xavier e Santo Antonio do Pinhal. Denominadas $A B C$ da Serra estão as cidades turísticas Santo Antonio do Pinhal, São Bento do Sapucaí e Campos do Jordão sendo que, Santo Antonio do Pinhal e Campos do Jordão se destacam no cultivo da truta pelo clima e altitude favorável. A Serra da Mantiqueira é, portanto uma grande área de preservação e de produção de trutas. As estimativas da Associação Brasileira de Truticultores - ABRAT indica que a produção brasileira está ao redor de 3.000 toneladas/ano (SATO, TABATA, TAKAHASHI, 2010).

A truta passou a ser um alimento típico da região, embora não nativa (originária da América do Norte), foi absorvida localmente beneficiada pelas condições deste terroir e hoje é hábito de consumo alimentar culturalmente internalizada e incorporada na gastronomia em diversos tipos de pratos servidos nos restaurantes. Também constitui atividade rural significativa pois está vinculada às condições únicas deste território: região de altitude e pressão atmosférica menor que contribui para diminuição da quantidade de oxigênio na água. Este último fator, ainda, a impossibilita de ser produzida em larga escala, o que denota também sua distinção. (SATO et al, 2011).

A história da truticultura em Campos do Jordão indica como principal vetor de inovação tecnológica a Estação Experimental de Salmonicultura de Campos do Jordão que tem realizado um trabalho de fomento e extensão rural e iniciou a propagação da criação na região, fornecendo ovos e alevinos para todo o Brasil. Está localizada no Horto Florestal - o primeiro e o maior parque estadual do Brasil, com a maior Floresta de araucárias das Américas, algumas com 500 anos (SATO; TABATA; TAKAHASHI, 2010).

Tema de diversos eventos locais e regionais, como os Festivais da Truta, ofertados em Santo Antônio do Pinhal e pela Associação Cozinha da Montanha de Campos do Jordão. A notoriedade da truta foi alcançada através da gastronomia oferecida nos restaurantes e hotéis da cidade e, de acordo com pesquisa realizada por Sato; Tabata; Takahashi (2010) junto aos restaurantes da cidade de Campos do Jordão existe uma forte associação do turismo com a truta, o chocolate e os fondues e aponta que 
especialmente a truta tem forte apelo gastronômico e está presente em todos os cardápios.

A truta arco íris (Oncorhynchusmykiss) é uma das espécies de peixes comercializadas no Brasil com algum tipo de processamento após-abate. Em geral, o peso de abate situa-se na faixa de 250-350 gramas, podendo no entanto serem encontradas no mercado, peixes de maiores tamanhos. O valor nutritivo e os preços dos peixes dependem da textura da carne, da composição química, do rendimento e dos fatores relacionados aos métodos de captura e beneficiamento (MACEDO-VIEGAS et al, 2008). Apresenta características biológicas tais como a coloração verde azeitona, com reflexos irisados no dorso e com pequenas manchas pretas em todo o corpo. Nos flancos possui uma lista rosada desde a cabeça à cauda. Desova uma vez por ano, entre outubro e março em zonas de águas correntes (TRUTA ARCO ÍRIS, 2014). A figura 1 ilustra a truta arco-íris (Oncorhynchusmykiss) cultivada na Serra da Mantiqueira.

\section{Figura 1: Truta arco-íris}

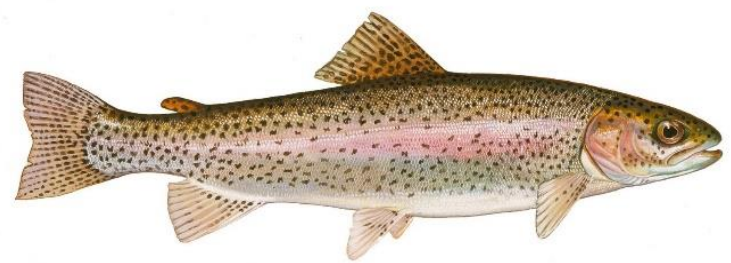

Fonte: (TRUTA ARCO IRIS, 2014).

Esta espécie de truta, pertence à família Salmonidae, sendo nativa da região do oeste da América do Norte (do Alaska até a Baixa California, no México) onde habita nos lagos e riachos. A truta arco-íris faz parte da tradição cultural das cidades e vilarejos na Serra da Mantiqueira há mais de cinquenta anos através da culinária, piscicultura e turismo de pesca esportiva (MAGALHÃES et al, 2002). De acordo com Soares (2008), a criação de peixes carnívoros no Brasil, desenvolveu-se com o emprego de espécies introduzidas entre elas, a truta arco-íris.
A composição da parte comestível dos peixes varia entre 70 a $85 \%$ de água, 20 a $25 \%$ de proteína, 1 a $10 \%$ de gordura, 0,1 a $1 \%$ de carboidratos e 1 a $1,5 \%$ de minerais. Essa composição é altamente variável da espécie, mas é comum a muitas espécies de peixes, o baixo conteúdo de gordura e a elevada quantidade de proteínas. A composição inicial da carne de peixe em cada 100 gramas: calorias $(93,7)$, gordura $(1,7 \mathrm{~g})$, proteínas $(19,6 \mathrm{~g})$, cálcio (27 mg), fósforo (19 mg), ferro (0,8 mg), vitamina B1 (0,04 mg) e vitamina B2 (0,08 mg) (OETERER, 2006).

O valor calórico dos peixes como alimento depende do teor de gordura. Com relação a localização da gordura, nos peixes gordos, estas se localizam dispersas por toda a carne do peixe, com 7 a $8 \%$ de gordura no salmão, arenque, cavala, pirarucu e tainha, com mais de $15 \%$ de gordura no atum, enguia e a merluza que contêm $16 \%$ de gordura. Nos peixes magros, a gordura está praticamente confinada ao fígado e possui 1 grama ou menos de gordura por 100 gramas de carne. Entre eles encontram-se o bacalhau, o badejo, o carapau, a carpa, o linguado, o peixe espada, a pescada, a pescadinha, o robalo e a truta (FAULHAUBER, 1988).

\subsection{Mapeamento dos produtores de truta pelo desenvolvimento rural regional da Serra da Mantiqueira e Vale do Paraíba paulistas, relato de uma experiência}

A natureza interdisciplinar da Gastronomia permite que ela dialogue com as ciências humanas, sociais aplicadas e da natureza. Envolve, portanto, mais do que a mistura de ingredientes, compreende noções antropológicas e sociológicas de regras, rituais, procedências, territórios, identidades, sustentabilidade e saudabilidade. Nos leva a pensar, então, em mais do que o simples ato de nutrir-nos. Segundo Pollan (2007,p.19),em sua obra O Dilema do Onívoro,

\footnotetext{
"Comer é um ato agrícola, disse, numa frase famosa, Wendell Berry. É também um ato ecológico, além de um ato político. Ainda que muito tenha sido feito para obscurecer esse fato bastante simples, o que e como comemos
} 
determinam, em grande parte, o que fazemos do nosso mundo - e o que vai acontecer com ele."

Assim, atualmente, é necessário vivenciar uma ideia mais complexa de qualidade alimentar, ou seja, aquela que nos permita compreender todas as interrelações entre a comida e o planeta e que promova alimentos que sejam bons em seus aspectos de sabor e nutricionais, mas limpos em relação ao seu cultivo e justos dentro de uma economia que valorize todos os envolvidos na cadeia.

Sob este contexto, o levantamento dos produtores de truta arco-íris foi inserido no projeto Mapeamento dos Sabores e Saberes da Serra da Mantiqueira e Vale do Paraíba em novembro de 2016. Este, de autoria e coordenação de Paula de Oliveira Feliciano em parceria com o Projeto Outras Viagens, também recebe colaboração do Projeto Integrador 2, matéria do segundo período do curso de superior de Tecnologia em Gastronomia do Senac Campos do Jordão.

Os antecedentes do mapeamento se iniciam a partir do segundo semestre de 2015, quando foi possível fortalecer definitivamente a intenção já existente em anos anteriores de realizar parceria de investigação científica de cunho proveitoso para a comunidade local. Acredita-se ser tarefa urgente no meio acadêmico da área da gastronomia interagir positivamente com a comunidade na qual está presente.

A autora iniciou a construção de uma plataforma online no GoogleMaps em maio de 2016. A intenção era a de estabelecer, dali em diante, uma rede de informações que pudesse ser acessada por todas as pessoas e que conectasse múltiplos interesses, ampliando também as possibilidades de atividades turísticas de base comunitária na região. Tal ferramenta foi apresentada em 8 de junho de 2016 no campus Campos do Jordão quando do estabelecimento, então, da colaboração da instituição de ensino.

Ao início focou-se na inserção de produtores agrícolas. No entanto, ao longo deste processo, verificou-se que seria de grande valia reunir não apenas estes, mas todos os que se dedicassem à cultivar, produzir e perpetuar a cultura alimentar da e na Serra da Mantiqueira e Vale do Paraíba paulistas. A aprendizagem envolvida visou integrar, por meio da colaboração de pesquisas acadêmicas dos alunos do Projeto Integrador 2, a plataforma desenvolvida à transformação da realidade local, possibilitando também a criação de novas relações de economia participativa incluindo o meio rural.

Figura 2: Ferramenta GoogleMaps “Mapeamento dos Sabores e Saberes da Serra da Mantiqueira e Vale do Paraíba" versão de maio de 2016

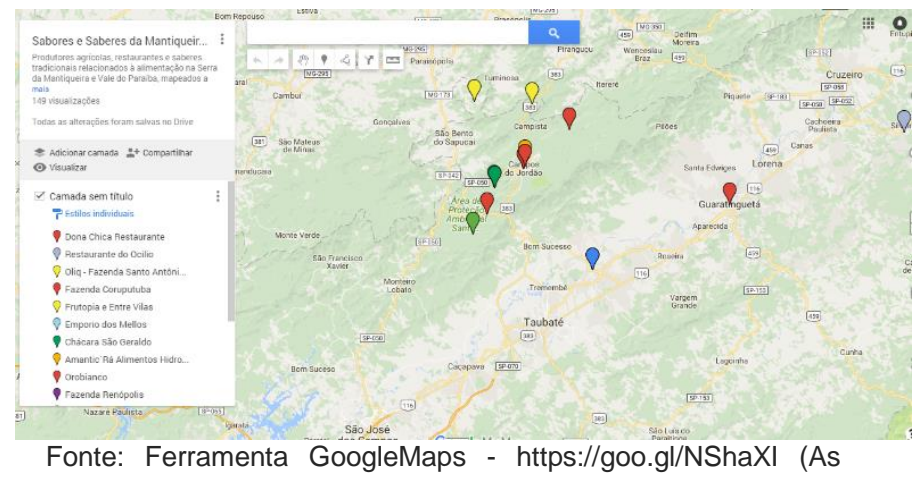

Autoras, 2016). 
Assim, conforme versão de maio de 2016 nomeada figura 2, foram relacionados 10 produtores agrícolas (Oliq, Fazenda Coruputuba, Frutopia, Chácara São Geraldo, Amantic'Rá, Orobianco, Fazenda Renópolis, Sítio do Bello, Arroz Ruzene e Sítio Quintal), 4 restaurantes (Dona Chica Restaurante, Restaurante do Ocílio, Entre Vilas e Empório dos Mellos) e 1 comunidade/artesãos do alimento (Feirinha dos Produtos da Terra APRUSAP).

Ao longo de 2016, igualmente estendeu-se este mapeamento da truticultura como resultado do trabalho de pesquisa das autoras deste artigo. Tais investigações também abrangem estudos teóricos e práticos sobre a relação entre gastronomia, território, sustentabilidade e saudabilidade. $\mathrm{O}$ que inclui aprofundamento de pesquisa e ações virtuosas sobre ingredientes locais, nativos ou assimilados, em prol do desenvolvimento rural local e possível atividade econômica de base comunitária auxiliada pela gastronomia que é peculiar.

Segundo a pesquisa cadastral na Associação Brasileira de Truticultores (ABRAT), somam-se 40 truticultores entre os estados de São Paulo, Minas Gerais e Rio de Janeiro, conforme tabela 1. Tal cadastro permite auferir a relação de empreendimentos dedicados ao cultivo de truta arco-íris, a cidade na qual se localiza e suas respectivas coordenadas geográficas, além da temperatura encontrada nas águas nas quais elas se desenvolvem.

Tabela 1: Truticultores cadastrados na Associação Brasileira de Truticultores (ABRAT), até 2016:

\begin{tabular}{|c|c|c|c|c|c|c|}
\hline \multirow[b]{2}{*}{$\mathrm{n}^{\circ}$} & \multirow[b]{2}{*}{$\begin{array}{l}\text { Nome do } \\
\text { empreendi } \\
\text { mento }\end{array}$} & \multirow[b]{2}{*}{ Cidade } & \multicolumn{3}{|c|}{ GPS } & \multirow{2}{*}{$\begin{array}{l}\text { Temperatura } \\
\text { no momento }\end{array}$} \\
\hline & & & $\begin{array}{l}\text { latitude } \\
\text { Sul (S) }\end{array}$ & $\begin{array}{l}\text { longitude } \\
\text { Oeste (W) }\end{array}$ & $\begin{array}{l}\text { altitude } \\
\text { (metros) }\end{array}$ & \\
\hline 01 & $\frac{\text { Pesca na }}{\text { Montanha }}$ & $\begin{array}{l}\text { São Bento do Sapucaí- } \\
\text { SP }\end{array}$ & $22^{\circ} 38,672^{\prime}$ & $45^{\circ} 37,152^{\prime}$ & 1636 & $14,0^{\circ} \mathrm{C}$ \\
\hline 02 & $\begin{array}{l}\text { ProAcqua - } \\
\text { Keber } \\
\text { Fleming }\end{array}$ & Campos do Jordão-SP & $22^{\circ} 40,490^{\prime}$ & $45^{\circ} 28,089^{\prime}$ & 1508 & $14,0^{\circ} \mathrm{C}$ \\
\hline 03 & $\begin{array}{l}\text { Parque dos } \\
\text { Lagos }\end{array}$ & $\begin{array}{l}\text { São Bento do Sapucaí- } \\
\text { SP }\end{array}$ & $22^{\circ} 40,320^{\prime}$ & $45^{\circ} 35,477^{\prime}$ & 1456 & $15,0^{\circ} \mathrm{C}$ \\
\hline 04 & $\frac{\text { Paulo }}{\text { Ribeiro }}$ & Pindamonhangaba-SP & $22^{\circ} 43,366^{\prime}$ & $45^{\circ} 27,163^{\prime}$ & 1860 & $13,0^{\circ} \mathrm{C}$ \\
\hline 05 & $\begin{array}{l}\text { Truticultura } \\
\text { NR }\end{array}$ & Sapucaí Mirim - MG & $22^{\circ} 47,796^{\prime}$ & $45^{\circ} 48,524^{\prime}$ & 1023 & $12,0^{\circ} \mathrm{C}$ \\
\hline 06 & Sítio Matão & $\begin{array}{l}\text { Sto Antônio do Pinhal- } \\
\text { SP }\end{array}$ & $22^{\circ} 51,735^{\prime}$ & $45^{\circ} 43,913^{\prime}$ & 1010 & $15,0^{\circ} \mathrm{C}$ \\
\hline 07 & Truta Azul & Campos do Jordão-SP & $22^{\circ} 46,982^{\prime}$ & $45^{\circ} 36,063^{\prime}$ & 1659 & $15,0^{\circ} \mathrm{C}$ \\
\hline 08 & $\frac{\text { Paulo das }}{\text { Trutas }}$ & $\begin{array}{l}\text { Camanducaia - Monte } \\
\text { Verde-MG }\end{array}$ & $22^{\circ} 51,994^{\prime}$ & $46^{\circ} 01,143^{\prime}$ & 1553 & $15,0^{\circ} \mathrm{C}$ \\
\hline 09 & $\begin{array}{l}\text { Recanto dos } \\
\text { Bambus }\end{array}$ & $\begin{array}{l}\text { Camanducaia - Monte } \\
\text { Verde-MG }\end{array}$ & $22^{\circ} 51,681^{\prime}$ & $46^{\circ} 04,486^{\prime}$ & 1425 & $19,0^{\circ} \mathrm{C}$ \\
\hline 10 & $\frac{\text { Roberto }}{\text { Comenale }}$ & $\begin{array}{l}\text { Camanducaia - Monte } \\
\text { Verde-MG }\end{array}$ & $22^{\circ} 47,327^{\prime}$ & $46^{\circ} 03,278^{\prime}$ & 1302 & $15,5^{\circ} \mathrm{C}$ \\
\hline 11 & $\begin{array}{l}\text { Recanto da } \\
\text { Floresta }\end{array}$ & Paraisópolis-MG & $22^{\circ} 40,787^{\prime}$ & $45^{\circ} 55,487^{\prime}$ & 1608 & $19,0^{\circ} \mathrm{C}$ \\
\hline 12 & Sítio & Paraisópolis-MG & $22^{\circ} 42,332^{\prime}$ & $45^{\circ} 56,301^{\prime}$ & 1756 & $18,0^{\circ} \mathrm{C}$ \\
\hline 13 & $\begin{array}{l}\text { Trutas da } \\
\underline{\text { Cachoeirinh }} \\
\underline{a}\end{array}$ & Campos do Jordão-SP & $22^{\circ} 43,483^{\prime}$ & $45^{\circ} 30,958^{\prime}$ & 1655 & $17,0^{\circ} \mathrm{C}$ \\
\hline 14 & $\frac{\text { Truticultura }}{\text { Lageado }}$ & Delfim Moreira-MG & $22^{\circ} 33,427^{\prime}$ & $45^{\circ} 21,181^{\prime}$ & 1144 & $20,0^{\circ} \mathrm{C}$ \\
\hline 15 & $\frac{\text { Ribeirão }}{\text { Grande }}$ & Pindamonhangaba-SP & $22^{\circ} 45,391^{\prime}$ & $45^{\circ} 26,678^{\prime}$ & 759 & $16,0^{\circ} \mathrm{C}$ \\
\hline 16 & Sítio Forelle & Pindamonhangaba-SP & $22^{\circ} 46,995^{\prime}$ & $45^{\circ} 29,483^{\prime}$ & 715 & $16,0^{\circ} \mathrm{C}$ \\
\hline 17 & $\begin{array}{l}\text { Pesque- } \\
\frac{\text { Pague do }}{\text { Thomas }}\end{array}$ & Guaratinguetá-SP & $22^{\circ} 43,046^{\prime}$ & $45^{\circ} 24,776^{\prime}$ & 1577 & $12,0^{\circ} \mathrm{C}$ \\
\hline 18 & $\begin{array}{l}\text { Fazenda da } \\
\text { Serra }\end{array}$ & Guaratinguetá-SP & $22^{\circ} 42,763^{\prime}$ & $45^{\circ} 24,022^{\prime}$ & 1228 & $13,0^{\circ} \mathrm{C}$ \\
\hline 19 & $\frac{\text { Fazenda do }}{\text { Charco }}$ & Delfim Moreira-MG & $22^{\circ} 37,261^{\prime}$ & $45^{\circ} 23,355^{\prime}$ & 1728 & $14,0^{\circ} \mathrm{C}$ \\
\hline 20 & Sítio & Delfim Moreira-MG & $22^{\circ} 29,424^{\prime}$ & $45^{\circ} 14,261^{\prime}$ & 1397 & $17,0^{\circ} \mathrm{C}$ \\
\hline 21 & $\frac{\text { Rio }}{\text { Comprido }}$ & Delfim Moreira-MG & $22^{\circ} 34,677^{\prime}$ & $45^{\circ} 22,215^{\prime}$ & 1346 & $14,0^{\circ} \mathrm{C}$ \\
\hline 22 & $\frac{\text { Piscicultura }}{\text { Escocesa }}$ & Delfim Moreira-MG & $22^{\circ} 33,462^{\prime}$ & $45^{\circ} 19,216^{\prime}$ & 1265 & $17,0^{\circ} \mathrm{C}$ \\
\hline 23 & $\begin{array}{l}\text { Truticultura } \\
\text { Sobradinho }\end{array}$ & Itamonte-MG & $22^{\circ} 20,811^{\prime}$ & $44^{\circ} 48,839^{\prime}$ & 1288 & $17,0^{\circ} \mathrm{C}$ \\
\hline 24 & $\frac{\text { Sítio da }}{\text { Pedra }}$ & Aiuruoca-MG & $22^{\circ} 03,638^{\prime}$ & $44^{\circ} 38,494^{\prime}$ & 1259 & $17,0^{\circ} \mathrm{C}$ \\
\hline 25 & $\begin{array}{l}\text { Fazenda } \\
\text { Hortência }\end{array}$ & Passa Quatro-MG & $22^{\circ} 27,210^{\prime}$ & $45^{\circ} 02,393^{\prime}$ & 1593 & $16,5^{\circ} \mathrm{C}$ \\
\hline 26 & Serrinha & Itatiaia - Penedo-RJ & $22^{\circ} 23,727^{\prime}$ & $44^{\circ} 33,214^{\prime}$ & 887 & $17,0^{\circ} \mathrm{C}$ \\
\hline 27 & $\frac{\text { Recanto das }}{\text { Trutas }}$ & $\begin{array}{l}\text { Bom Jardim de Minas- } \\
\text { MG }\end{array}$ & $22^{\circ} 02,455^{\prime}$ & $44^{\circ} 10,607^{\prime}$ & 1219 & $15,5^{\circ} \mathrm{C}$ \\
\hline 28 & $\begin{array}{l}\text { Bosque dos } \\
\text { Pinheiros }\end{array}$ & $\begin{array}{l}\text { Bom Jardim de Minas- } \\
\text { MG }\end{array}$ & $22^{\circ} 01,263^{\prime}$ & $44^{\circ} 10,509^{\prime}$ & 1226 & $17,0^{\circ} \mathrm{C}$ \\
\hline 29 & $\begin{array}{l}\text { Truticultura } \\
\frac{\text { Santo }}{\text { Antonio }}\end{array}$ & Bocâina de Minas-MG & $22^{\circ} 13,693^{\prime}$ & $44^{\circ} 34,240^{\prime}$ & 1364 & $16,2^{\circ} \mathrm{C}$ \\
\hline 30 & $\frac{\text { Truticultura }}{\text { Anthomaz }}$ & Mirantão-MG & $22^{\circ} 15,126^{\prime}$ & $44^{\circ} 28,781^{\prime}$ & 1000 & $18,0^{\circ} \mathrm{C}$ \\
\hline 31 & $\begin{array}{l}\text { Fazenda } \\
\text { Pedra } \\
\text { Negra }\end{array}$ & Bocâina de Minas-MG & $22^{\circ} 12,454^{\prime}$ & $44^{\circ} 32,145^{\prime}$ & 1223 & $17,0^{\circ} \mathrm{C}$ \\
\hline 32 & $\frac{\text { Sítio Queda }}{\text { D'Áqua }}$ & Sapucaí-Mirim-MG & $22^{\circ} 44,157^{\prime}$ & $45^{\circ} 54,475^{\prime}$ & 1486 & $16,0^{\circ} \mathrm{C}$ \\
\hline 33 & $\frac{\text { Trutas }}{\text { Romari }}$ & Camanducáia-MG & $22^{\circ} 48,022^{\prime}$ & $45^{\circ} 59,595^{\prime}$ & 1529 & $15,5^{\circ} \mathrm{C}$ \\
\hline 34 & Hélio Gorni & Camanducáia-MG & $22^{\circ} 46,679^{\prime}$ & $46^{\circ} 02,336^{\prime}$ & 1367 & $18,0^{\circ} \mathrm{C}$ \\
\hline 35 & $\begin{array}{l}\text { Truticultura } \\
\frac{\text { Monte }}{\text { Verde }}\end{array}$ & Camanducáia-MG & $22^{\circ} 47,191^{\prime}$ & $46^{\circ} 00,410^{\prime}$ & 1410 & $18,0^{\circ} \mathrm{C}$ \\
\hline 36 & $\begin{array}{l}\text { UPD } \\
\frac{\text { Campos do }}{\text { Jordão }}\end{array}$ & Campos do Jordão-SP & $22^{\circ} 40,510^{\prime}$ & $45^{\circ} 28,200^{\prime}$ & 1520 & $16,0^{\circ} \mathrm{C}$ \\
\hline 37 & Aqua & Bananal-SP & $22^{\circ} 47,869^{\prime}$ & $44^{\circ} 27,816^{\prime}$ & 1166 & $17,0^{\circ} \mathrm{C}$ \\
\hline 38 & $\frac{\text { Pesqueiro }}{\text { Zé Pequeno }}$ & Cunha-SP & $23^{\circ} 11,922^{\prime}$ & $45^{\circ} 00,315^{\prime}$ & 1133 & $18,0^{\circ} \mathrm{C}$ \\
\hline 39 & $\frac{\text { Vivenda das }}{\text { Meninas }}$ & Cunha-SP & $23^{\circ} 13,776^{\prime}$ & $45^{\circ} 00,812$ & 1147 & $18,0^{\circ} \mathrm{C}$ \\
\hline 40 & $\frac{\text { Sítio Santa }}{\text { Fé - Ubiraci }}$ & Guarulhos-SP & $23^{\circ} 17,496^{\prime}$ & $46^{\circ} 22,745^{\prime}$ & 856 & $17,0^{\circ} \mathrm{C}$ \\
\hline
\end{tabular}

Fonte: Portal da Associação Brasileira de Truticultores (ABRAT, 2016). 
O recorte desta presente pesquisa será estabelecido nos limites da Serra da Mantiqueira e Vale do Paraíba paulistas, que abrangem as imediações do Centro Universitário Senac Campos do Jordão.

O levantamento permitiu verificar quinze propriedades dedicadas ao cultivo de trutas nessas regiões. Estão presentes nas cidades paulista de Campos do Jordão (4), São Bento do Sapucaí (2), Santo Antonio do Pinhal (1), Pindamonhangaba (3), Guaratinguetá (2), Cunha (2) e Bananal (1).

As temperaturas médias das águas variam de $12^{\circ} \mathrm{C}$ a $18^{\circ} \mathrm{C}$, sendo a menor medição, de $12^{\circ} \mathrm{C}$, verificada na propriedade Pesque-Pague do Thomas em Guaratinguetá e a maior, de $18^{\circ} \mathrm{C}$, em Pesqueiro Zé Pequeno e Vivenda das Meninas, ambas no município de Cunha.

De acordo com Tabata e Portz (2004 apud SATO et al, 2011), as melhores faixas de temperaturas para o crescimento das trutas varia entre $15^{\circ} \mathrm{C}$ e $17^{\circ} \mathrm{C}$ e, para os índices reprodutivos, devem estar próximo à $10^{\circ} \mathrm{C}$, condições particularmente presentes em regiões de altitude. Outro fator relevante na questão é a qualidade e volume da água já que ambos determinam a oferta de oxigênio disponível e influenciam a quantidade de peixes a serem produzidos.
Tabela 2: Truticultores na Serra da Mantiqueira e Vale do Paraíba paulistas, até 2016:

\begin{tabular}{|c|c|c|c|c|c|c|}
\hline \multirow[b]{2}{*}{$\mathrm{n}^{\circ}$} & \multirow[b]{2}{*}{$\begin{array}{c}\text { Nome do } \\
\text { empreendimento }\end{array}$} & \multirow[b]{2}{*}{ Cidade } & \multicolumn{3}{|c|}{ GPS } & \multirow{2}{*}{$\begin{array}{l}\text { Temperatura } \\
\text { no momento }\end{array}$} \\
\hline & & & $\begin{array}{l}\text { latitude } \\
\text { Sul (S) }\end{array}$ & $\begin{array}{l}\text { Iongitude } \\
\text { Oeste (W) }\end{array}$ & $\begin{array}{l}\text { altitude } \\
\text { (metros) }\end{array}$ & \\
\hline 01 & Pesca na Montanha & $\begin{array}{l}\text { São Bento do Sapucaí- } \\
\text { SP }\end{array}$ & $22^{\circ} 38,672^{\prime}$ & $45^{\circ} 37,152^{\prime}$ & 1636 & $14,0^{\circ} \mathrm{C}$ \\
\hline 02 & $\begin{array}{l}\text { ProAcqua - Keber } \\
\text { Fleming }\end{array}$ & Campos do Jordão-SP & $22^{\circ} 40,490^{\prime}$ & $45^{\circ} 28,089^{\prime}$ & 1508 & $14,0^{\circ} \mathrm{C}$ \\
\hline 03 & Parque dos Lagos & $\begin{array}{l}\text { São Bento do Sapucaí- } \\
\text { SP }\end{array}$ & $22^{\circ} 40,320^{\prime}$ & $45^{\circ} 35,477^{\prime}$ & 1456 & $15,0^{\circ} \mathrm{C}$ \\
\hline 04 & Paulo Ribeiro & Pindamonhangaba-SP & $22^{\circ} 43,366^{\prime}$ & $45^{\circ} 27,163^{\prime}$ & 1860 & $13,0^{\circ} \mathrm{C}$ \\
\hline 05 & Sítio Matão & $\begin{array}{l}\text { Sto Antônio do Pinhal- } \\
\text { SP }\end{array}$ & $22^{\circ} 51,735^{\prime}$ & $45^{\circ} 43,913^{\prime}$ & 1010 & $15,0^{\circ} \mathrm{C}$ \\
\hline 06 & Truta Azul & Campos do Jordão-SP & $22^{\circ} 46,982^{\prime}$ & $45^{\circ} 36,063^{\prime}$ & 1659 & $15,0^{\circ} \mathrm{C}$ \\
\hline 07 & $\begin{array}{l}\text { Trutas da } \\
\text { Cachoeirinha }\end{array}$ & Campos do Jordão-SP & $22^{\circ} 43,483^{\prime}$ & $45^{\circ} 30,958^{\prime}$ & 1655 & $17,0^{\circ} \mathrm{C}$ \\
\hline 08 & Ribeirão Grande & Pindamonhangaba-SP & $22^{\circ} 45,391^{\prime}$ & $45^{\circ} 26,678^{\prime}$ & 759 & $16,0^{\circ} \mathrm{C}$ \\
\hline 09 & Sítio Forelle & Pindamonhangaba-SP & $22^{\circ} 46,995^{\prime}$ & $45^{\circ} 29,483^{\prime}$ & 715 & $16,0^{\circ} \mathrm{C}$ \\
\hline 10 & $\begin{array}{l}\text { Pesque-Pague do } \\
\text { Thomas }\end{array}$ & Guaratinguetá-SP & $22^{\circ} 43,046^{\prime}$ & $45^{\circ} 24,776^{\prime}$ & 1577 & $12,0^{\circ} \mathrm{C}$ \\
\hline 11 & Fazenda da Serra & Guaratinguetá-SP & $22^{\circ} 42,763^{\prime}$ & $45^{\circ} 24,022^{\prime}$ & 1228 & $13,0^{\circ} \mathrm{C}$ \\
\hline 12 & $\begin{array}{l}\text { UPD Campos do } \\
\text { Jordão }\end{array}$ & Campos do Jordão-SP & $22^{\circ} 40,510^{\prime}$ & $45^{\circ} 28,200^{\prime}$ & 1520 & $16,0^{\circ} \mathrm{C}$ \\
\hline 13 & Aqua & Bananal-SP & $22^{\circ} 47,869^{\prime}$ & $44^{\circ} 27,816^{\prime}$ & 1166 & $17,0^{\circ} \mathrm{C}$ \\
\hline 14 & $\begin{array}{l}\text { Pesqueiro Zé } \\
\text { Pequeno }\end{array}$ & Cunha-SP & $23^{\circ} 11,922^{\prime}$ & $45^{\circ} 00,315^{\prime}$ & 1133 & $18,0^{\circ} \mathrm{C}$ \\
\hline 15 & $\begin{array}{l}\text { Vivenda das } \\
\text { Meninas } \\
\end{array}$ & Cunha-SP & $23^{\circ} 13,776^{\prime}$ & $45^{\circ} 00,812$ & 1147 & $18,0^{\circ} \mathrm{C}$ \\
\hline
\end{tabular}

Fonte: Adaptado do portal da Associação Brasileira de Truticultores (ABRAT, 2016).

Desta forma, é possível também verificar que as faixas da altitude nas cidades selecionadas variam entre $715 \mathrm{~m}$ e $1860 \mathrm{~m}$, ambos registros na cidade de Pindamonhangaba.

De posse destas informações, e na tentativa de torná-las mais visíveis com a proposta de seu mapeamento, abre-se espaço para a reflexão sobre a possibilidade de estabelecimento de uma denominação de origem que associe a truta arco-íris e a região da Mantiqueira, o que beneficiaria o desenvolvimento rural local.

A seguir, pode-se observar espacialmente os truticultores pesquisados e incluídos na Ferramenta GoogleMaps "Mapeamento dos Sabores e Saberes da Serra da Mantiqueira e Vale do Paraíba" disponíveis a partir da versão de 16 de novembro de 2016. 
Figura 3: Ferramenta GoogleMaps "Mapeamento dos Sabores e Saberes da Serra da Mantiqueira e Vale do Paraíba" versão 16 de novembro de 2016

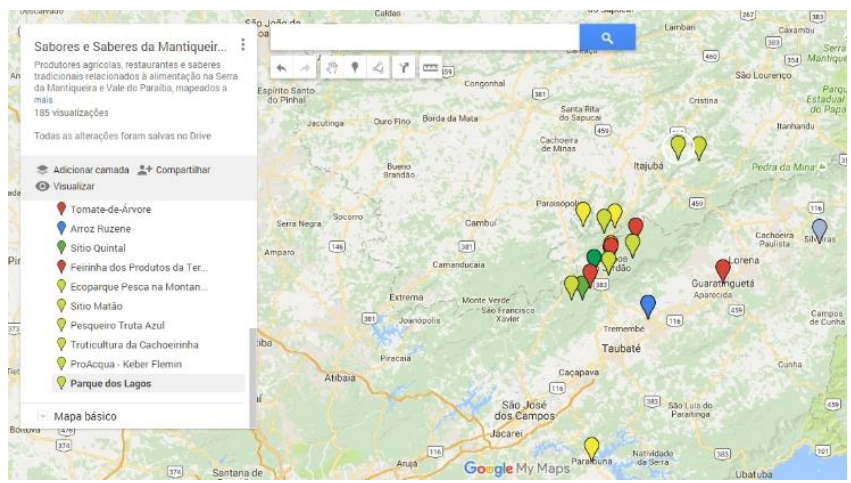

Fonte: Ferramenta GoogleMaps - https://goo.gl/NShaXI (As Autoras, 2016).

De acordo com Oliveira (2014), processos educativos em práticas sociais propiciam interações entre pessoas, entre os indivíduos e as comunidades, grupos entre si e, numa ideia mais ampla, entre nações. Tais relações podem promover enraizamentos, desenraizamentos ou a criação de novas raízes. Os objetivos de processos educativos em práticas sociais são

- repassar conhecimentos, valores, tradições, posições e posturas diante da vida;

- suprir necessidades de sobrevivência, de manutenção material e simbólica de pessoas, grupos ou comunidade;

- buscar o reconhecimento dessas necessidades pela sociedade;

- controlar, expandir a participação política de pessoas, de grupos, de comunidades em decisões da sociedade mais ampla;

- propor e/ou executar transformações na estrutura social, nas formas de racionalidade, de pensar e de agir ou articular-se para mantê-las;

- garantir direitos sociais, culturais, econômicos, políticos, civis;

- corrigir distorções e injustiças sociais;

- buscar reconhecimento, respeito, valorização das culturas e da participação cidadã de grupos sociais, étnico-raciais marginalizados pela sociedade:

- pensar, refletir, discutir e executar ações.

(OLIVEIRA, 2014, p.33).

Além da capacidade de fomentar o desenvolvimento rural local pelo vínculo a uma qualidade exclusivamente regional, compreendida por fatores naturais e humanos, permitiria estabelecer, "parâmetros de segurança alimentar sanitária, nutricional e produtos, que na sua origem tenham compromisso com a sustentabilidade ambiental e social e, também, para proteger o produto local, garantindo a manutenção dos produtores em suas atividades no campo". (SATO et al, 2011)

O mapeamento dos produtores de truta pelo desenvolvimento rural regional da Serra da Mantiqueira e Vale do Paraíba paulistas vai de encontro ao aproveitamento de um processo de aprendizagem em conjunto à valorização dos saberes rurais locais.

\section{Considerações finais}

Se o aprender, reflexo dos mais avançados e atuais estudos no mundo da Educação, nos coloca frente ao desenvolvimento de uma complexidade de qualidades profissionais e humanas importantes, o aprendizado no Ensino Superior nos impõe a percepção consciente de sua função transformadora e necessidade da dimensão duradoura para que seja socialmente útil no mundo contemporâneo.

Os estímulos sensoriais representam o ponto principal do desenvolvimento do sistema nervoso, das emoções e da consciência. As experiências vividas têm papel determinante na construção das percepções, dos pontos de vista e dos posicionamentos conscientes, questões de importância ímpar na educação dos indivíduos, seja para vida pessoal ou profissional. Educar os sentidos facilita a criação de conexões e memórias, que renovarão a compreensão de mundo e de atitudes individuais.

Trabalhar com pesquisa que visa ao mapeamento dos produtores de truta locais vai ao encontro de uma escola menos artificial, aproximando o estudante da realidade da vida, entendendo sua natureza problemática e que é preciso resolvê-la. Demonstra que não existem matérias isoladas, pois a investigação inclui todos os aspectos da aprendizagem, como a leitura, a escrita, o cálculo, a expressão artística, atitudes, valores, enfim, a compreensão do mundo ao redor. 
A alimentação tem papel fundamental na vida do ser humano primeiro pelo aspecto fisiológico e, a gastronomia tem papel de aproximação social, agindo beneficamente no fortalecimento das áreas rurais porque tem contornos culturais, sociais, lúdicos, artísticos, de saúde e bem-estar. Os alimentos e bebidas de um país, região ou cidade são capazes de expressar a cultura, os costumes, as crenças e histórias de um povo e seu uso territorial. A delimitação das formas de preparo, técnicas utilizadas e ingredientes é dada tanto pela disponibilidade de meios como pelas referências culturais desse povo. Ou seja, o que é comestível em um lugar, pode não o ser em outro e o que se tem à mesa em um lugar é único; sendo assim, o alimento pode ser um elemento essencial da valorização e desenvolvimento dos territórios.

Juntar o contexto da gastronomia brasileira, em toda sua expressão de território, somados aos níveis histórico, político e social, é estratégia fundamental para o aproveitamento do ensino formal e na busca do real sentido da educação no século $\mathrm{XXI}$.

Somente desta forma, o estudante desenvolverá autonomia, segurança e maturidade suficientes para compreender que não pode limitar sua existência à passividade, mas deve aprender a buscar informações e organizá-las, registrá-las, compará-las, discuti-las e criticá-las. Incorporando, verdadeiramente, os conhecimentos para além de sua vida acadêmica, mas igualmente à pessoal e da sua comunidade, mantendo uma abertura contínua em sua vida para experenciar e incorporar em si próprio processos de mudança.

\section{Referências}

\section{ASSOCIAÇÃO BRASILEIRA DE TRUTICULTORES -}

ABRAT, 2016. Listagem de truticultores cadastrados. São Paulo: ABRAT. Disponivel em: < http://www.aquicultura.br/abrat/database2.htm>.

Acesso em: nov 2016.
CANESQUI, Ana Maria (Org.) Antropologia e nutrição: um diálogo possível. Organizado por Ana Maria Canesqui e Rosa Wanda Diez Garcia. Rio de Janeiro: Editora FIOCRUZ, 2005. 306 p. (Coleção Antropologia e Saúde) Disponível em: $<$ http://pessoal.utfpr.edu.br/suseli/arquivos/Antropo logia_e_Nutricao_um_dialogo_pos sivel.pdf\#page=133>. Acesso em: maio. 2017.

CARNEIRO, Henrique. Comida e sociedade: uma história da alimentação. São Paulo: CampusElsevier, 2003.

DÓRIA, Carlos Alberto. A culinária materialista: construção racional do alimento e do prazer gastronômico. São Paulo: Editora Senac São Paulo, 2009.

FAULHAUBER, C. A importância de um sistema de Inspeção e Controle de Qualidade dos Produtos da Pesca. In: Seminário sobre controle na indústria de pescado. Santos, 1988. Anais. 1988.

FRANCO, G. Tabela de Composição de alimentos, 9 edição, São Paulo, 2008.

GOLDSCHMIDT, Andrea Inês; MACHADO, Dilma Terezinha de Moraes; STAEVIE, Eliana Madalena Souza; MACHADO, Ana Luiza Grohe; FLORES, Marluce Ferreira. A importância do lúdico e dos sentidos sensoriais humanos na aprendizagem do meio ambiente. XIII Seminário Internacional de Educação - indisciplina e violência na escola: cenários e direções. Cachoeira do Sul: ULBRA, $2008 . \quad$ Disponível em: $<$ http://www.sieduca.com.br/2008/index2411.html? principal=lista_trabalhos\&eixo $=1 \&$ modalidade $=1>$ Acesso em set 2016.

GRATÃO, Lúcia Helena; MARANDOLA JR, Batista Eduardo. Sabor da, na e para Geografia. Geosul, Florianópolis, v. 26, n.51, p59-74, jan./jun. 2011. 
HERRMANN, Gisela; COSTA,Cláudia Maria Rocha. Boas práticas na Truticultura. Apoio: Agência Paulista de Tecnologia dos Agronegócios; Secretaria de Agricultura e Abastecimento do Governo do Estado de São Paulo. Belo Horizonte: Valor Natural, 2012.

MACEDO-VIEGAS, et al. Rendimento e composição centesimal de filés in natura e pré-cozido em truta arco-iris (Oncorhychus mykiss). Acta Scientiarum, Maringá, v.24, n.4, p. 1191-1195,2002.

MACIEL, Maria Eunice. Uma cozinha à brasileira. Revista Estudos Históricos. Rio de Janeiro, nำ33, jan.-jun. 2004, p. 25-39. Disponível em: $<$ http://bibliotecadigital.fgv.br/ojs/index.php/reh/arti cle/viewArticle/2217>. Acesso em: maio. 2017.

MAGALHÃES et al. Ocorrência de trutas (Oncorhynchus mykiss) no alto rio Aiuruóca e tributários, bacia do rio Grande, Minas Gerais, Brasil. Bol. Mus. Biol. Mello Leitão, 14:33-40, dez, 2002.

MENEZES, Maria Cristina Pinto de. A formação de alunos (as) num curso superior de Gastronomia: aprendizagem, cultura e cidadania. 2005. $11 \mathrm{f}$. Dissertação (Mestrado em Educação) UNINOVE, São Paulo, 2005. Disponível em: <http://www.uninove.br/PDFs/Mestrados/Educaçã o/eventos/COMUNICAÇÃO 4.pd f >. Acesso em: maio. 2017.

MIYAZAKI, Márcia H. Ensinando e aprendendo gastronomia: percursos na formação de professores. 2006. 115 f. Dissertação (Mestrado em Educação) -Universidade Metodista de Piracicaba, Piracicaba, 2006.

MONTANARI, Massimo. Comida como cultura. Tradução de Letícia Martins de Andrade. São Paulo: Editora Senac São Paulo, 2008.
OLIVEIRA, Maria Waldenez (org) et al. Processos Educativos em Práticas Sociais: reflexões teóricas e metodológicas sobre pesquisa educacional em espaços sociais. São Paulo: EdUFSCAR, 2014.

OETTERER et al. Fundamentos de Ciência e Tecnologia de alimentos. Barueri: São Paulo, 2006.

PESCADOR, R. Aspecto nutricionais dos lipídios nos peixes: Uma Revisão de Literatura. Monografia. Universidade de Brasília, Brasília- DF, setembro de 2006.

PETRINI, Carlo; BOGLIOTTI, Carlo; RAVA, Rinaldo; SCAFFIDI,Cinzia. A Centralidade do Alimento: documento do congresso 2012-2016.Disponível em <http://www.slowfoodbrasil.com/campanhas-emanifestos/598-a-centralidade-do-alimento> Acesso em set 2016.

POLLAN, Michael. O dilema do onívoro. São Paulo: Intrínseca, 2007.

POULAIN, Jean Pierre. Sociologias da Alimentação: os comedores e o espaço social alimentar. Tradução: Rossana Pacheco da Costa Proença, Carmen Sílvia Rial, Jaimir Conte. $2^{\underline{a}}$ ed. 286 p. Florianópolis: Ed da UFSC, 2013.

SATO, Geni Satiko; Yara Aiko TABATA; Neuza S.TAKAHASHI. Truta de Campos do Jordão, valorização do produto local através do turismo e da gastronomia. In: CONGRESSO LATINOAMERICANO DE SOCIOLOGIA RURAL, 8, Porto de Galinhas, 2010. Anais eletrônicos... Porto de Galinhas, 2010. Disponível em: $<$ http://www.alasru.org/wpcontent/uploads/2011/07/GT4-GENI-SATIKOTRUTA-DE-CAMPOS-DO-JORD\%C3\%83O2.pdf>. Acesso em: 02 set. 2013. 
SATO, GeniSatiko. TABATA, Yara Aiko. TAKAHASHI, Neuza Sumiko. Truta de Campos do Jordão, valorização do produto local através da indicação geográfica do turismo e da gastronomia. Informações Econômicas, SP, v.41, n.3, mar. $2011 . \quad$ Disponível em: <http://www.iea.sp.gov.br/ftpiea/publicacoes/IE/20 11/tec5-0311. pdf> Acesso em nov 2016.

SOARES, E.C. Cultivo Intensivo de espécies carnívoras. Rev. Bras. Enga. Pesca. 3 (2), jul, 2008.

TACO. Tabela Brasileira de Composição de Alimentos, NEPA/ Unicamp, 4⿳亠丷a edição, 2011.

TRUTA ARCO-ÍRIS. Disponível em: $<$ http://eamb.ufp.pt/document/truta/biologia.html\#tr uta íris>. Acesso: 12 fev. 2014.

TUAN, Yi-Fu. Topofilia: um estudo da percepção, atitudes e valores do meio ambiente. São Paulo: Difel, 1980.

WÄTZOLD, Tim. Proclamação da cozinha brasileira como parte do processo de formação da identidade nacional no império brasileiro 18221889. Teses de doutorado - Universidade de Colônia, Alemanha. 348 p. Belo Horizonte: TCS Ed., 2012. Disponível em: $<$ http://www.academia.edu/4344330/Proclama\%C 3\%A7\%C3\%A3o_da_Cozinha_Brasileira_como_p arte_do_processo_de_forma\%C3\%A7\%C3\%A3o_ da_identitade_nacional_no_Imperio_Brasileiro> Acesso em dez 2016. 